\title{
Pengetahuan Berhubungan dengan Anemia Remaja di Pesantren Modern Ummul Qura Al- Islam Bogor Tahun 2016
}

\author{
Aning Subiyatin ${ }^{1}$, Laily Mudrika ${ }^{2}$ \\ ${ }^{1,2}$ Program Studi Diploma III Kebidanan Fakultas Kedokteran dan Kesehatan Universitas Muhammadiyah
}

\begin{abstract}
Abstrak
Berdasarkan Riskesdas 2013, dilaporkan bahwa angka kejadian anemia secara nasional adalah sebesar $21,7 \%$, dimana $23,9 \%$ terjadi pada perempuan, wanita memiliki pravelensi tertinggi mengalami anemia, termasuk diantaranya remaja putri. Tujuan dari penelitian adalah untuk mengetahui faktor-faktor yang mempengaruhi anemia pada remaja putri kelas XI di PM Ummul Qur Al-Islami. Design penelitian menggunakan cross sectional. Populasi penelitian ini adalah seluruh remaja putri kelas XI di PM Ummul Quro Al-Islami. Sampel berjumlah 100 remaja putri. Pengambilan sampel dilakukan dengan menggunakan teknik total Sampling. Analisis yang digunakan adalah bivariat. Sebanyak $52 \%$ remaja putri mengalami anemia, pengetahuan gizi berhubungan dengan anemia Pvalue=0,0001 (OR 11,182, CI95\% 4,400-28,414), sedangkan yang tidak berhubungan adalah pola menstruasi dan pola makan. Kejadian anemia di kelas XI di PM Ummul Quro Al-Islami masih tinggi, pengetahuan sangat berperan dalam kejadian anemia. Perlu adanya peningkatan pengetahuan gizi melalui penyuluhan.
\end{abstract}

Kata Kunci: Anemia, remaja putri, pola menstruasi, pola makan, pengetahuan gizi.

\section{Knowladge Assosiated Anemia on Addolance in PM Ummul Qura Al-Islam Bogor On 2016}

\begin{abstract}
Based Riskesdas 2013, it was reported that the incidence of anemia nationally is $21.7 \%$, of which $23.9 \%$ were in women, women have the highest prevalence are anemic, including young women.

The purpose of the study was to determine the factors that influence anemia in adolescent girls in class XI Ummul Quro Islamic Boarding School

This type of research is quantitative research with descriptive method with cross sectional study design. The population in this study were all teenage girls in class XI Ummul Quro Islamic Boarding School. Sample of 100 adolescent girls. Sampling was done by using total sampling technique.

The result showed $52 \%$ of respondents are anemic, $18 \%$ of respondents experiencing irregular mesntruasi $12(66.7 \%)$ of people are anemic, $41 \%$ have a good eating pattern $17(41.5 \%)$ of people megalami anemia, 53\% of respondents had knowledge bad nutrition 41 (77.4\%) of people experiencing anemia. The results also show there is only one variable that is related to anemia I $\mathrm{n}$ adolescent girls as knowledge of nutrition with pvalue $=0.0001$ (OR 11,182, CI95\% from 4.400 to 28.414).

The inference that the majority of respondents who experienced anemia is the respondents who had knowledge of nutrition is not good, it means the knowledge of nutrition has a relationship with anemia in adolescent girls.
\end{abstract}

Keywords: Anemia, adolescent girls, menstrual pattern, dierty habit, nutrition knowledg

K oresp ondensi: Aning Subiyatin, Program Studi Ilmu Kesehatan Masyarakat, Fakultas Ilmu Kesehatan Universitas Pembangunan Nasional V eteran Jakarta, J1. RS. Fatmawati, Pondok L abu Jakarta 12450, mobile 081318517656 , e-mail. aning.ridwan@yahoo.com

Aning, Pengetahuan Berhubungan Dengan Anemia Remaja 


\section{Pendahuluan}

Anemia menyebabkan darah tidak cukup mengikat dan mengangkut oksigen dari paruparu ke seluruh tubuh. Bila oksigen yang tidak diperlukan tidak cukup, maka akan berakibat pada sulitnya berkonsentrasi, sehingga prestasi belajar menurun, daya tahan fisik rendah sehingga mudah lelah, akifitas fisik menurun, mudah sakit karena daya tahan tubuh rendah, akibatnya jarang masuk sekolah atau bekerja. ${ }^{1}$

Akibat jangka panjang anemia pada remaja putri adalah apabila remaja putri nantinya hamil, maka dia tidak mampu memenuhi kebutuhan zat-zat gizi bagi dirinya dan juga janin dalam kandungannya serta pada masa kehamilan anemia ini dapat meningkatkan frekuensi komplikasi, resiko kematian maternal, angka prematuritas, BBLR dan kematian perinatal.

Remaja merupakan tahap dimana seseorang mengalami sebuah masa transisi menuju remaja. Remaja adalah tahap umur yang datang setelah masa kanak-kanak berakhir, ditandai pertumbuhan fisik yang cepat. Remaja didalam masyarakat dikenal dengan berbagai istilah yang menunjukkan kelompok umur yang tidak termasuk kanakkanak tetapi bukan pula dewasa. Pada umumnya, anemia banyak terjadi pada wanita dan remaja putri dibandingka dengan pria. Sangat disayangkan adalah kebanyakan penderita tidak tahu atau tidak menyadari, bahkan ketika tahupun menganggap anemia sebagai masalah sepele.

Anemia adalah suatu kondisi medis dimana kadar hemoglobin kurang dari normal. Kadar HB normal pada remaja putri adalah
$>12 \mathrm{gr} / \mathrm{dl}$. Remaja putri dikatakan anemia jika kadar HB $<12$ gr/dl.

MenurutWHO 2014, di negara berkembang terdapat 370 juta wanita yang menderita anemia dengan $41 \%$ wanita tidak hamil. Di india, pravelensi anemia dari $45 \%$ telah dilaporkan untuk remaja putri. Di indonesia prevalensi anemia $26 \%$ untuk anak perempuan dan $11 \%$ untuk anak lakilaki.Berdasarkan Riskesdas 2013, dilaporkan bahwa angka kejadian anemia secara nasional adalah sebesar $21,7 \%$, dimana $18,4 \%$ terjadi pada laki-laki dan 23,9 \% terjadi pada perempuan. Sedangkan berdasarkan kriteria usia 5-14 tahun mencapai $26,4 \%$ dan pada usia 15-24 tahun mencapai 18,4\%. Berdasarkan semua kelompok umur tersebut, wanita memiliki pravelensi tertinggi mengalami anemia, termasuk diantaranya remaja putri.

Remaja putri mempunyai resiko lebih tinggi terkena anemia daripada remaja putra. Alasan pertama karena setiap bulan pada remaja putri mengalami menstruasi. Seorang wanita yang mengalami menstruasi yang banyak selama lebih dari lima hari dikhawatirkan akan kehilangan zat besi, sehingga diperlukan zat besi pengganti lebih banyak daripada wanita yang menstruasinya tiga hari dan sedikit

Remaja putri termasuk golongan rawan menderita anemia karena remaja putri dalam masa pertumbuhan dan setiap bulan mengalami menstruasi yang menyebabkan kehilangan zat besi, sedangkan dalam masa pertumbuhan remaja putri membutuhkan zat gizi yang lebih tinggi termasuk zat besi. 
Alasan kedua adalah karena remaja putri seringkali menjaga penampilan, keinginan untuk tetap langsing atau kurus sehingga berdiet dan mengurangi makan. Diet yang tidak seimbang dengan kebutuhan gizi akan menyebabkan tubuh kekurangan gizi penting seperti zat besi.

Selain itu, remaja putri biasanya sangat memperhatikan bentuk badan, sehingga banyak yang membatasi konsumsi makan dan banyak pantangan terhadap makanan seperti pada diet vegetarian.

Kebiasaan makan yang tidak sehat termasuk penyebab terjadi anemia pada remaja putri, salah satu faktor yang mempengaruhi kebiasaan makan remaja adalah pengetahuan.

Pengetahuan yang kurang menyebabkan remaja banyak memilih untuk makan diluar rumah dan biasanya makanan yang dikonsumsi remaja memilik kandungan zat besi yang rendah sehingga zat besi yang diserap oleh tubuh hanya sedikit.

Tujuan dari penelitian ini adalah untuk mengetahui mengetahui faktor-faktor yang

\section{Hasil}

Hasil pemeriksaan kadar $\mathrm{Hb}$ remaja putri di kelompokkan menjadi 2 kategori yaitu anemia dan tidak anemia (normal). Kategori mempengaruhi anemia pada remaja putri kelas XI di PM Ummul Quro Al-Islami.

\section{Metode}

Rancangan penelitian ini menggunakan penelitian deskriptif kuantitatif. Pendekatan yang digunakan pada desain ini adalah cross sectional. Populasi dalam penelitian ini adalah semua remaja putri kelas XI di PM PM Ummul Quro Al-Islami Leuwiliang Bogor yang berjumlah 100 siswi, sampelnya adalah total sampling. Sumber data yang diambil merupakan data primer, alat ukurnya kuisoner dengan cara ukur wawancara, yang dilakukan oleh peneliti secara langsung.

Variabel dependen dalam penelitian ini adalah anemia pada remaja putri adapun variabel independennya adalah pola menstruasi, pola makan dan pengetahuan gizi.

Analisis data menggunakan software statistik dengan uji chi square. Tempat penelitian di PM Ummul Quro Al-Islami Bogor. Pelaksanaan pengumpulan data dilakukan pada tanggal 04 Mei 2016.

anemia adalah responden yang mempunyai kadar $\mathrm{Hb}<12 \mathrm{gr} \%$, sedangkan kategori tidak anemia adalah responden yang mempunyai kadar $\quad \mathrm{Hb} \quad>=\quad 12 \mathrm{gr} \%$ 
Gambar 1. Distibusi Frekuensi Anemia Pada Remaja Putri Kelas XI di PM PUmmul Quro AlIslami.

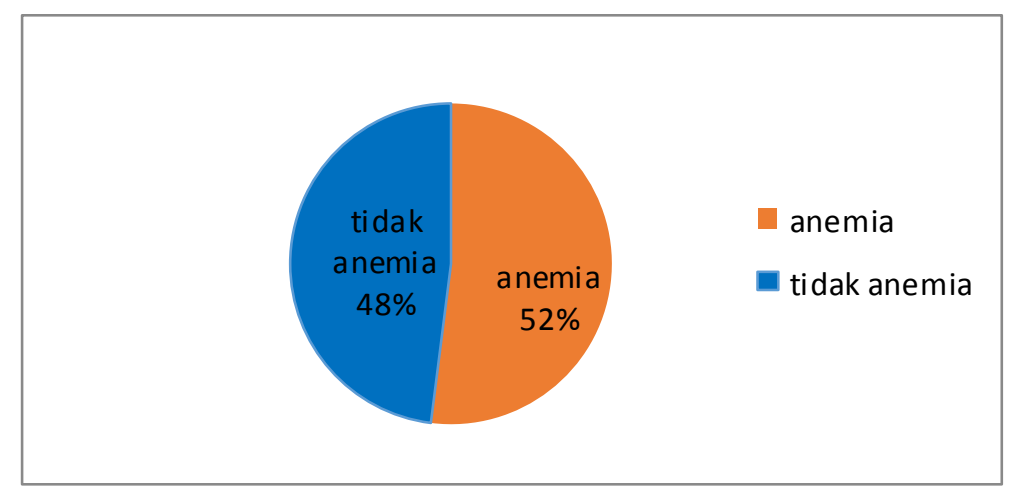

Anemia adalah kekurangan kadar hemoglobin $(\mathrm{Hb})$ dalam darah yang disebabkan kekurangan zat gizi yang di perlukan untuk pembentukan hemoglobin. Kadar $\mathrm{Hb}$ normal pada remaja perempuan adalah $12 \mathrm{gr} / \mathrm{dl}$. Remaja dikatakan anemia jika kadar $\mathrm{Hb}<12 \mathrm{gr} / \mathrm{dl}^{16}$ Berdasarkan hasil penelitian dapat diketahui bahwa prevalensi anemia pada remaja putri di PM Ummul Quro

Tabel 1. Pola Menstruasi, Pola Makan dan Pengetahuan Gizi terhadap Anemia pada Remaja Putri kelas XI di PM Ummul Quro Al-Islami

\begin{tabular}{lcc}
\hline Variabel & n & \% \\
\hline Menstruasi & & \\
Tidak teratur & 18 & 18 \\
Teratur & 82 & 82 \\
Pola Makan & & \\
Tidak Baik & 41 & 41 \\
Baik & 59 & 59 \\
Pengetahuan Gizi & \\
Tidak Baik & 53 & 53 \\
Baik & 47 & 47 \\
Total & $\mathbf{1 0 0}$ & $\mathbf{1 0 0}$ \\
\hline
\end{tabular}

Besarnya pravelensi anemia di PM Ummul Quro Al-Islami dapat dikarenakan dari makanan yang dikonsumsi oleh santri kurangnya pengetahuan tentang gizi makanan yang telah dikonsumsi sehingga pravelensi
Al-islami sebesar 52\% (52 orang), sedangkan yang tidak mengalami anemia sebesar $48 \%$ (48 orang). Hasil penelitian ini tidak jauh berbeda dengan penelitian yang dilakukan oleh Handayani (2011) terhadap remaja putri di SMAN Kijang, Kecamatan Bintan Timur dimana diketahui pravelensi anemia sebesar $47,1 \%$.

anemia cukup tinggi. Keberhasilan penanganan dan penanggulangan anemia pada remaja putri akan tercapai apabila ada kerja sama antara lintas sekunder, seperti dinas kesehatan, pihak pengelola pesantren, dukungan keluarga dan masyarakat. Beberapa cara dapat dilakukaan seperti penyuluhan kesekolah-sekolah mengenai anemia, pola makan yang baik tidak melakukan diet, cara pencegahan dan pengebotan anemia.

Hasil analisis menstruasi bahwa remaja putri yang mengalami frekuesnsi menstruasi normal ada 82 orang $(82 \%)$ dan mengalami frekuensi menstruasi tidak normal ada 18 orang (18\%). Frekuensi mentruasi normal adalah menstruasi yang terjadi sekali dalam satu bulan, remaja dalam usia reproduksi normalnya mengalami menstruasi satu kali dalam sebulan dengan volume darah 2-5 kali 
mengganti pembalut dalam sehari dan lama menstruasi tidak lebih dari hari. ${ }^{19}$ Hasil penelitian terhadap pola menstruasi mayoritas responden mengalami menstruasi normal.

Analisis pola makan dibagi menjadi dua pengukuran, yaitu pola makan baik terdapat sebanyak 59 orang (59\%) sedangkan yang tidak baik sebanyak 41 orang (41\%). Dari hasil penelitian didapatkan 89 orang yang tidak melakukan diet dan 11 orang yang melakukan diet. Pola makan baik frekuensi makan 3 kali sehari, mengkosumsi makanan 4 sehat 5 sempurna tidak melakukan diet atau memantang makanan dan tidak mengkonsumsi junkfood. Hasil penelitian menunjukkan bahwa mayoritas responden memiliki pola makan baik dan tidak melakukan diet.

Analisis pengetahuan gizi di bagi menjadi dua, yaitu pengetahuan gizi baik terdapat 47 orang $(47 \%)$ sedangkan pengentahuan gizi tidak baik terdapat 53 orang $(53 \%)$. Nilai tertinggi pengetahuan gizi adalah 34 dan terendah adalah 9, dari hasil penelitian di dapatkan mean 25,93, medain 27,00 dan modus 31. Pengetahuan gizi baik adalah dimana seseorang mampu mengetahui kandungan gizi makanan yang dikonsumsi. Mayoritas responden memiliki pengetahuan gizi baik artinya responden tahun akan gizi makanan yang

dikonsumsi

\section{Tabel 2. Hubungan Pola Menstruasi, Pola Makan, dan Pengetahuan Gizi terhadap Anemia pada Remaja Putri kelas XI di PM Ummul Quro Al-Islami}

\begin{tabular}{lllr}
\hline Variabel & Kategori & OR(95\% CI) & $\begin{array}{l}\text { P } \\
\text { value }\end{array}$ \\
\hline $\begin{array}{llll}\text { Pola } \\
\text { menstruasi }\end{array}$ & $\begin{array}{l}\text { Tidak } \\
\text { teratur }\end{array}$ & 2,100 & 0,200 \\
\cline { 2 - 3 } & Teratur & $0,719-6,131$ & \\
\hline Pola makan & \multicolumn{2}{c}{0,104} \\
\cline { 2 - 3 } & Tidak baik & 0,486 & \\
\hline Pengetahuan & Tidak baik & $0,216-1,092$ & \\
gizi & Baik & $4,400-28,414$ & \\
\hline $\begin{array}{l}\text { Pengetahuan } \\
\text { gizi }\end{array}$ & Tidak baik & 11,182 & 0,001 \\
\cline { 2 - 3 } & Baik & $4,400-28,414$ &
\end{tabular}

Berdasarkan tabel 2, terlihat bahwa pola menstruasi tidak berhubungan $P$ value $=0,200(\mathrm{OR} 2,1, \mathrm{CI} 95 \% \quad 0,719-6,131)$ artinya tidak ada hubungan antara pola menstruasi dengan anemia pada remaja putri.

Hasil analisis hubungan antara pola makan dengan anemia pada remaja putri di peroleh $p$ value $=0,104(\mathrm{OR} \quad 0,486, \mathrm{CI} \quad 95 \%$ 0,216-1,092) artinya tidak ada hubungan antara pola makan dengan anemia pada remaja putri, sedangkan hasil analisis hubungan antara pengetahuan gizi dengan anemia pada remaja putri diperoleh $p$ value $=0,0001(\mathrm{OR} 11,182$, CI95\% 4,400-28,414) artinya ada hubungan 
antara pengetahuan gizi dengan anemia pada remaja putri. Dari hasil analisi diperoleh pula nilai $\mathrm{OR}=11,182$ artinya remaja putri yang memiliki pengetahuan gizi tidak baik memiliki peluang 11,182 kali mengalami anemia dibandingkan dengan remaja putri yang memiliki pengetahuan gizi baik.

\section{Simpulan}

Hasil analisis univariat tentang anemia didapatkan dari 100 responden 52\% mengalami anemia dan $48 \%$ tidak mengalami anemia. Hasil analisis menstruasi bahwa remaja putri yang mengalami frekuesnsi menstruasi normal ada 82 orang $(82 \%)$ dan mengalami frekuensi menstruasi tidak normal ada 18 orang (18\%). Analisis pola makan dibagi menjadi dua pengukuran, yaitu pola makan baik terdapat sebanyak 59 orang (59\%) sedangkan yang tidak baik sebanyak 41 orang (41\%). Analisis pengetahuan gizi di bagi menjadi dua, yaitu pengetahuan giz i baik terdapat 47 orang (47\%) -sedangkan pengentahuan gizi tidak baik terdapat 53 orang $(53 \%)$.

\section{Saran}

Diharapkan agar dilakukan penelitian lebih lanjut tentang anemia agar dapat mengetahui lebih banyak variabel variabel yang dapat menyebabkan anemia. Diharapkan bagi tenaga kesehatan unutk mengadakan penyuluhan tentang anemia disekolah-sekolah agar siswa-siswi memiliki pengetahuan lebih baik tentang anemia maka angka kejadian anemia pada remaja akan berkurang.

\section{Daftar Pustaka}

1. Depkes RI.2008.”Gizi Dalam Angka Sampai Dengan Tahun 2007'. Jakarta: Direktorat Jenderal Bina Kesehatan Masyarakat.

2. Hayati, RM. 2010. Pegetahuan dan Sikap Anemia Defesiensi Besi dan Dampaknya terhadap Kesehatan Reproduksi di MAL IAIN Medan Tahun 2009/2010. Medan: Universitas Sumatera Utara. 12

3. Syamsu Yusuf L.N. (2011). Psikologi Perkembangan Anak dan Remaja. Bandung: PT. Remaja Rosdakarya.

4. Proverawati, Atikah.2011 Anemia dan Anemia Kehamilan. Yogyakarta : Nuha Medika

5. Riset Kesehatan Dasar (Riskesdas). 2013. Penelitian dan pengembangan kesehatan. Jakarta: Kementrian Kesehatan Republik Indonesia.

6. Arisman, 2007. Gizi Dalam Daur Kehidupan Jakarta: Penerbit Buku Kedokteran

7. Arisman. (2009). Buku Ajar Ilmu Gizi Keracunan Makanan, Jakarta: EGC. Hal 93.

8. Djani Sedaioetama, Achmad. 2007. Ilmu Gizi. Jakarta

9. Khomsan A. 2005. Pangan dan Gizi untuk Kesehatan2. Bogor: Departemen Masyarakat. Fakultas Ekologi Manusia, Institusi Pertanian Bogor. 
10. Soetjiningsih. (2007). Buku Ajar Tumbuh Kembang Remaja dan Permasalahannya. Jakarta: Sagung Seto

11. Santrock, John W. 2007. Remaja, Edisi 11 (Benedictine Widyasinta, Penerjemah). Jilid 1. Jakarta: Erlangga

12. Depkes RI. 2007. Modul Pelatihan Pelayanan Kesehatan Peduli Remaja (PKPR). Jakarta: Departemen Kesehatan RI 2007.

13. Sayogo, Savitri. 2006. "Gizi Remaja Putri”. Jakarta: Balai Penerbit FKUI.

14. Arimurti, Ida. 2009. "Makan Bersama Keluarga Membentuk Pola Makan Remaja Lebih Baik”.

15. Ayustaningwarno. Fitriyono. 2009. "Tontonan Televisi Mempengaruhi Pola Makan Remaja."

16. Tarwono,Ns, DKK. Kesehatan Remaja Problem dan Solusinya. Jakarta: Salemba Medika 2009

17. Suryaprajogo, Nadine. Kupas Tuntas Kesehatan Remaja Dari A-Z. Yogyakarta Diglosia Printika 2009
18. Proverawati, A. \& Misaroh, S. Menarche (Menstruasi Pertama Penuh Makna). Yogyakarta : Muha Medika;2009

19. Hestiantoro, dkk 2008. "Masalah Gangguan Haid dan Infertilitas". Jakarta Penerbit FKUI.

20. Satyaningsih, Elsa. 2007. "Anemia Gizi Pada Remaja Putri SMK Amaliyah Sekadau Kalimantan Barat Tahun 2007”. Depok: Thesis FKMUI.

21. Astawan, Made dan Andreas L Kasih. 2008. Khasiat Warna-Warni Makanan. Jakarta: Penerbit PT. Gramedia Pustaka Utama.

22. Saidin, S, dkk. Hubungan Kebiasaan Makan Pagi Dengan Konsentrasi Belajar”. Bogor : Pusat Penelitian dan Pengembangan Gizi dan Makanan Departemen Kesehatan RI

23. Notoatmojo Soekitdjo. 2011. "Kesehatan Masyarakat”. Jakarta : PT Rineka Cipta

24. Susanto Priyo Hastono. "Analisis Data Kesehatan”. Fakultas Kesehatan Masyarakat Universitas Indonesia” 2007. 